\title{
La aplicación restringida de Rawls en la ética de la empresa: una concepción política de la teoría de los stakeholders y de la moralidad de los mercados*
}

Recibido: abril 12 de 2010 | Aprobado: diciembre 16 de 2011

\author{
Marc A. Cohen** \\ cohenm@seattleu.edu
}

\begin{abstract}
Resumen El presente ensayo sostiene que los principios de justicia de Rawls proporcionan una fundamentación normativa para la teoría de los stakeholders. Los principios articulan (en un nivel abstracto) los derechos de los ciudadanos; estos derechos crean intereses en todos los aspectos de la sociedad, incluyendo el ámbito de la actividad económica; y, por lo tanto, los stakeholders -en calidad de ciudadanos- tienen intereses legítimos en dicho ámbito. Así, la obra de Rawls nos obliga a fundamentar cuestiones de la ética de la empresa en la filosofía política: los derechos e intereses de los stakeholders (que son los derechos e intereses de los ciudadanos en la esfera económica) están protegidos en el nivel institucional, por lo que no pueden venir determinados por los directivos ni las corporaciones.
\end{abstract}

\section{Palabras clave}

Rawls, teoría de los stakeholders (fundamentación normativa), teoría del contrato social, enfoque de los Mercados Morales, ética de las organizaciones.

The Narrow Application of Rawls in Business Ethics: A Political Conception of Both Stakeholder Theory and the Morality of Markets

\begin{abstract}
This paper argues that Rawls' principles of justice provide a normative foundation for stakeholder theory. The principles articulate (at an abstract level) citizens' rights; these rights create interests across all aspects of society, including in the space of economic activity; and therefore, stakeholders -as citizens- have legitimate interests in the space of economic activity. Rawls work therefore presses us to ground questions of business ethics in political philosophy: stakeholder rights and interests (which are citizens' rights and interests in the economic context) are protected at the institutional level and are not to be determined by managers or corporations.
\end{abstract}

\section{Key words}

Rawls, stakeholder theory (normative foundations), social contract theory, Moral Markets approach, organizational ethics.
* Traducción de José Manuel Carballido Cordero (Colegio San Ignacio, Medellín, Colombia) publicada por primera vez en español con las debidas autorizaciones del autor y de los editores del Journal of Business Ethics, en el cual el texto fue originalmente publicado (Vol. 97, No. 4, 2010, pp. 563-579).

** Doctor en Filosofía, Universidad de Pensilvania-Estados Unidos. Profesor asistente, Departamento de Gerencia y Departamento de Filosofía, Universidad de Seattle-Estados Unidos. Agradezco a John Dienhart, Maria Derdevandis y Jeff Helmreich por sus múltiples y útiles sugerencias, y por su estímulo. 


\section{Introducción}

El presente trabajo explora la aplicación de la obra de Rawls en la ética de la empresa. Concretamente, sugiero que los principios de justicia de Rawls proporcionan una fundamentación normativa para la teoría de los stakeholders ${ }^{1}$. Los principios articulan (en un nivel abstracto) los derechos de los ciudadanos; estos derechos crean unos intereses en todos los aspectos de la sociedad; algunos de estos intereses acompañarán la actividad económica y, por lo tanto, los stakeholders -en calidad de ciudadanos- tienen intereses legítimos sobre las transacciones económicas, inclusive sobre las transacciones en las que no formen parte directamente. Freeman (1994) también recurre a Rawls para asegurar una fundamentación normativa de la teoría de los stakeholders, pero Child y Marcoux (1999) cuestionan la forma en que Freeman recurre a Rawls, tanto teórica como prácticamente. Mi enfoque sigue una estrategia diferente a la de Freeman, y responde directamente al problema que plantean Child y Marcoux.

Mi tesis general es que los principios de justicia proporcionan ya un conjunto amplio de derechos y obligaciones en el ámbito de la actividad económica; estas obligaciones afectan a directivos y personas de negocios, pero se tratan y se protegen a nivel institucional. Y si la estructura básica resultara ser insuficiente, si no se protegieran los intereses de los ciudadanos, entonces la sociedad -no sólo el sector empresarial, sino la sociedad en su conjunto- no puede ser justa. Esta línea de argumentación es el tema de la Primera parte en el presente ensayo.

Aproximarse a la teoría de los stakeholders en términos de derechos de los ciudadanos sugiere una interpretación política del enfoque de Boatright sobre el concepto de Mercado Moral. Y dicha aproximación toca otra cuestión, a saber: ¿qué derechos y obligaciones adicionales poseen los agentes económicos, más allá de los garantizados por su rol como ciudadanos? (Nótese que a lo largo del presente trabajo toda referencia a una ética de la actividad eco-

Por stakeholders se entienden básicamente cinco grupos de interés de la empresa: clientes, empleados, proveedores, propietarios y la sociedad en general. [N. del T.]. 
nómica remite a los derechos y obligaciones más allá de los que ya acompañan a los ciudadanos.) El propio Rawls rechazaría la idea de unos derechos y obligaciones adicionales que acompañen a la actividad económica por dos razones: porque cualquier derecho y obligación institucionalizados violarían la libertad de los ciudadanos (por eso no deberíamos imponer derechos y obligaciones adicionales, ni siquiera tener expectativas sobre ellos), y porque no se dará la base para el acuerdo entre los agentes económicos en asuntos de justicia (por lo que no podemos considerar estos derechos como un tema del consenso social). De esta manera, la obra de Rawls nos obliga a reconceptualizar el lugar de las reivindicaciones éticas en el contexto económico. Estos dos temas, el de los derechos y obligaciones adicionales que puedan acompañar a los agentes económicos, y el del enfoque de Boatright sobre los Mercados Morales, constituyen el asunto de la Segunda parte del presente ensayo. Y finalmente, en el Apéndice abordaré tres cuestiones de orden más técnico sobre mi aplicación de la obra de Rawls al contexto de la ética de las organizaciones propuesta por Phillips y Margolis (Phillips y Margolis, 1999).

La literatura referente a la ética de la empresa hace un uso libre de los procedimientos y conceptos de Rawls - un contrato social hipotético, el velo de la ignorancia, y la posición original. Pero la sustancia de su obra tiene implicaciones importantes para la ética de la empresa, las cuales aún no han sido exploradas en su totalidad; por "sustancia" entiendo aquí tanto el contenido particular de ambos principios de justicia, como el concepto político de justicia en Rawls. Marens (Marens, 2007) también admite esta posición, es decir, la de que la ética de la empresa ha abrazado los métodos de Rawls, pero ha ignorado la sustancia de su obra (en el contexto de una exploración histórica de la influencia que la obra de Locke ha tenido sobre la ética de la empresa). Así pues, mi aplicación de Rawls a la teoría de los stakeholders es "restringida", en el sentido que toma esta sustancia como punto de partida. Pero quiero aclarar que mi objetivo no es ni legislar sobre lo que sea o no "rawlsiano", ni tampoco limitar de algún modo el debate y la aplicación de la obra de Rawls en la ética de la empresa.

Dos salvedades antes de continuar: en primer lugar, el debate que sigue a continuación asume la obra de Rawls y la aplica (excep- 
to en mi discusión sobre el pluralismo, donde aplico un punto de vista más limitado o prudente). Nada de lo que diga sobre la comprensión de su obra deberá levantar controversia excepto, quizás, la parte $\mathrm{C}$ del Apéndice. Sin embargo, yo no defiendo el concepto rawlsiano de justicia como equidad, ni tampoco justifico la transformación que ocurre en su obra posterior -aunque indirectamente sugiero que Rawls ofrece un punto de partida plausible para la ética de la empresa. Y segundo, el presente artículo trata la aplicación de la obra de Rawls exclusivamente en el escenario estadounidense. La ética de la empresa en el contexto internacional, que incluye cuestiones sobre los derechos humanos en la ética de la empresa, plantea preguntas adicionales sobre la obra El derecho de gentes de Rawls. Tales preguntas necesitan ser abordadas en un artículo independiente, el cual espero poder terminar en un futuro cercano.

\section{Primera parte: Los principios de justicia como funda- mentación de la teoría de los stakeholders}

Los contornos de la obra de Rawls son bien conocidos. Las partes en el contrato social seleccionan principios de justicia. Los legisladores extraen de esos principios de justicia los derechos y obligaciones particulares que disfrutan los ciudadanos, y diseñan la estructura básica para proteger dichos deberes y hacer cumplir tales obligaciones. Esta estructura básica incluye las instituciones legales, sociales y económicas que componen un sistema de cooperación social de la sociedad -la constitución política, el sistema de propiedad (los derechos y deberes asociados a la posesión de propiedad) y el sistema de mercados para las transacciones económicas. Los derechos y obligaciones particulares que sostienen los ciudadanos son fuertes, en el sentido de que los miembros de la comunidad pueden reclamar haber sido tratados injustamente, y exigir compensación si no se respetan estos derechos y no se cumple con las obligaciones. Algunos de estos derechos y obligaciones acompañarán a los ciudadanos en su actuación como agentes económicos.

Según Rawls, el mercado libre amenaza la sociedad entendida como un sistema equitativo de cooperación social, donde la idea de equidad se articula en los principios de justicia: "Un sistema de 
mercado libre se debe establecer en el marco de instituciones políticas y legales que ajusten la tendencia a largo plazo de las fuerzas económicas para impedir concentraciones excesivas de propiedad y riqueza, en especial las que pueden conducir a la dominación política" (Justicia como equidad, §13)². Así, los legisladores incluyen un conjunto de autorizaciones y restricciones para las asociaciones, con el fin de prevenir las ya mencionadas concentraciones y acumulaciones -para, de este modo, proteger a los ciudadanos, y preservar el valor equitativo de los derechos y oportunidades de éstos. Estas autorizaciones y restricciones se realizan también en la estructura básica. Existe aquí la posibilidad de una variante: ya que tanto el contexto social como las historias sociales difieren, los legisladores podrían toparse con diferentes sistemas, y el resultado podría ser un sistema socioeconómico como el de Suecia u otro como el de la economía de los Estados Unidos (aunque nótese lo siguiente: no estoy sugiriendo con esto que el sistema económico estadounidense hoy por hoy sea compatible con los principios de justicia, sino simplemente que dichos principios pueden llevarse a cabo de diferentes maneras).

Los derechos y obligaciones sustentados por los ciudadanos, y las autorizaciones y restricciones incluidas en las asociaciones, todos ellos permiten que se logre el consenso de la sociedad en torno a las obligaciones y las restricciones que se deberían incluir en las actividades individuales y colectivas dentro del contexto económico. Por ejemplo, el compromiso de Rawls con la equitativa igualdad de oportunidad prohibiría la discriminación de las prácticas laborales en el lugar de trabajo (ese principio tendría además otras implicaciones de largo alcance, por ejemplo, requeriría alguna forma de disponer capital para las personas que deseen abrir un negocio, de la misma manera que lo hace actualmente la Administración del Pequeño Negocio en los Estados Unidos). La discriminación se evita por medio de las instituciones sociales y políticas, y en este sentido los principios de justicia se realizan en la estructura básica, pero los

\footnotetext{
Este punto sugiere además que la explotación económica debería ser estimada en términos sociales, y no en términos puramente económicos. Véase mi artículo "Explotación económica en términos sociales (no económicos)", en la actualidad en revisión.
} 
principios protegen derechos, de ahí que se apliquen en todos los aspectos de la sociedad, incluida la actividad económica. En breve proporcionaré más ejemplos de la aplicación de los principios en el ámbito económico. En este apartado, la idea general es que debemos considerar como fundamentales al menos algunos intereses de los stakeholders para el funcionamiento de la sociedad como un todo orgánico. (La palabra "algunos" en la frase anterior se refiere a los intereses incluidos en los principios de justicia; en la segunda parte me ocuparé del estatuto de los intereses adicionales de los stakeholders como agentes económicos.)

La aplicación de esta idea sobre la obra de Rawls: según Rawls, los ciudadanos eligen los principios de justicia situándose tras el velo de la ignorancia, el cual tiene la función de restringir las consideraciones que pueden tener lugar en el proceso de deliberación. Las restricciones aseguran que los factores moralmente irrelevantes no puedan afectar a las decisiones tomadas por la partes del contrato social, factores como el del conocimiento de la posición que la persona tiene en la sociedad. Freeman (1994) crea un segundo velo de la ignorancia para especificar los derechos de los stakeholders, y para garantizar una fundamentación filosófica de tales derechos: "Una manera de entender la equidad en este contexto [el de los contratos económicos, y con él, el de la actividad económica entendida en sentido general] es argumentar junto con Rawls que un contrato es justo si las partes llegan a un acuerdo ignorando sus estados concretos" (Freeman, 1994: 416). Desde aquí Freeman presenta seis principios, los cuales constituyen su "Doctrina de los Contratos Equitativos". En el "corazón normativo" de esta versión se encuentra la "igualdad básica entre los stakeholders en términos de sus derechos morales, pues éstos se plasman en el momento de la firma" (Freeman, 1994: 415).

Child y Marcoux (1999) cuestionan la lógica interna del artículo de Freeman: argumentan que las partes situadas tras este segundo velo de la ignorancia no aceptarían sus seis principios $-\mathrm{y}$, en particular, rechazarían el Principio de las Externalidades de Freeman. Podemos enunciar dicho principio del siguiente modo: "Si un contrato entre $\mathrm{A}$ y $\mathrm{B}$ impone un coste sobre $\mathrm{C}$, entonces $\mathrm{C}$ posee la opción 
de convertirse en una parte del contrato, por lo se renegocian sus términos" (Freeman, 1994: 416). Freeman añade: "La racionalidad de esta condición es clara. Cada stakeholder querrá garantías de que no será C". Child y Marcoux consideran el siguiente caso: A desea alquilar el escaparate de $\mathrm{B}$ para vender camisas hawaianas; $\mathrm{C}$ vive cerca del escaparate, y las camisas hawaianas atentan contra su sensibilidad estética; por tanto, $\mathrm{C}$ corre con un coste como resultado del contrato entre A y B. De acuerdo con el principio de Freeman, a $\mathrm{C}$ se le debe dar la oportunidad de convertirse en parte del contrato y renegociar así sus términos. Pero esto no puede ser correcto: a C no se le debería permitir interferir simplemente porque a ella no le guste la ropa (aunque podríamos imaginar otros escenarios en los que la preocupación de C fuera legítima; por ejemplo, si A quisiera abrir un club de striptease y la entrada estuviera al lado de un colegio infantil). Por tanto, Freeman necesita encontrar algún parámetro que le ayude a identificar cuándo las externalidades le dan una razón legítima a $\mathrm{C}$ para interferir, y también precisa de alguna base para clasificar tales demandas en caso de darse disputas entre los stakeholders, aunque Child y Marcoux no observan este punto adicional. Ambos muestran -a mi modo de ver de forma convincenteque el argumento de Freeman carece de recursos para proporcionar el parámetro que necesita (en su discusión sobre las protecciones endógenas y exógenas para C) (Child y Marcoux, 1999: 214-216). Y, por lo tanto, requerimos de otra fundamentación normativa para la teoría de los stakeholders ${ }^{3}$.

En este punto, los dos principios de justicia ya proporcionan exactamente lo que Freeman quiere, sin necesidad de un contrato adicional ni un caso adicional de la posición original: los principios de justicia articulan (en un nivel abstracto) los derechos de los ciudadanos; tales derechos proporcionan a los ciudadanos unos intereses sociales legítimos en el ámbito de la actividad económica; lo cual muestra que los stakeholders - en calidad de ciudadanos- poseen intereses legítimos en

\footnotetext{
Child y Marcoux ofrecen otro ejemplo: "Supongamos que a nosotros dos no nos gusta en absoluto la canción 'Big Man with a Gun', del grupo Nine-Inch Nail, y que con cada venta de dicha canción nos sintiéramos peor. ¿Tendríamos el derecho de vetar todas las ventas de la canción? Si de este modo nos convertimos en partes del contrato, y la unanimidad es la norma (como sugiere el principio de gobierno de Freeman), entonces pareciera que deberíamos tener ese derecho -y con el beneplácito de Freeman" (Child y Marcoux, 1999: 222, n. 38).
} 
transacciones y actividades económicas, formen o no directamente parte de ellas.

Este argumento garantiza la normatividad de la teoría de los stakeholders, es decir, que los principios de justicia de Rawls proporcionan la fundamentación normativa de los derechos de los stakeholders como ciudadanos ${ }^{4}$. Como se ha dicho ya, los legisladores determinan los derechos particulares que los ciudadanos ostentan: determinan cuándo la actividad económica amenaza los derechos (y las oportunidades) de los ciudadanos; en tal caso, los ciudadanos poseen un interés social legítimo y, por tanto, los legisladores deben ordenar la estructura básica de tal modo que estos intereses sociales sean protegidos. Al hacer esto, los legisladores estarán proporcionando el parámetro que Child y Marcoux solicitan (con razón). Así pues, el contrato social adicional y, con él, el segundo caso de posición original y el conjunto adicional de principios para el contrato equitativo, resultan innecesarios.

En este punto se da una distinción importante: los principios de justicia garantizan los intereses de los ciudadanos en el ámbito de la actividad económica, ya sean partícipes directamente o no; pero no garantizan los intereses de los agentes económicos que participan en transacciones particulares donde sus intereses difieren o van más allá de los de los ciudadanos. Contemplar la teoría de los stakeholders en términos de los intereses de los ciudadanos incluye un conjunto de stakeholders apropiadamente amplio, es decir, que dicho enfoque incluye stakeholders afectados por una corporación pero no como partes directas de las transacciones económicas. [Esto es lo que yo entiendo aquí por "apropiadamente" -mi enfoque de la teoría de los stakeholders incluirá los tipos normativos y derivativos, de la manera en que Phillips (Phillips, 2003: 28-29) usa estos términos, y los stakeholders primarios y secundarios, tal y como son definidos por Freeman (Freeman et al., 2007: 6-8). A lo que me refiero es a lo

\footnotetext{
Véase Donaldson y Preston (Donaldson y Preston, 1995), quienes distinguen las concepciones normativas de los derechos de los stakeholders frente a las concepciones instrumentales. Nótese que este enfoque -basado en la obra de Rawls- también podría ser fecundo en el terreno de los derechos humanos para la ética de la empresa. Los principios rawlsianos están pensados para ser aplicados en acuerdos políticos dentro de los Estados Unidos, por lo tanto, para poder aplicar la obra de Rawls tendríamos que remitirnos a su Derecho de gentes, y no a los principios de justicia. Esto es parte de mi proyecto ya mencionado en la Introducción del presente artículo.
} 
siguiente: fundamentar la teoría en los derechos y obligaciones de los ciudadanos no excluye grupos de stakeholders.] Por otra parte, al concebirla de esta manera, deja de ser una teoría de la gerencia: los derechos de los stakeholders (que son derechos de los ciudadanos en el contexto económico) son protegidos en el nivel institucional, y no vienen determinados por directivos o corporaciones. Por esta razón mi anterior afirmación, la de que los principios de justicia proporcionan a Freeman "exactamente" lo que él quiere, puede resultar un tanto exagerada -si lo que Freeman quiere es una teoría de la gerencia. Dicho esto, los principios le dan a Freeman la sustancia de lo que él busca, a saber, el reconocimiento explícito de los derechos de los stakeholders, y también la protección institucional para esos derechos (lo cual puede ir más allá de lo que él desea), incluso si los derechos así concebidos son un asunto abordado por las instituciones y el proceso político mismo, y no por los directivos.

Incluso siendo este enfoque apropiadamente general como yo sugiero, es posible que la teoría de los stakeholders entendida a la manera de Freeman pretenda ser más fuerte. Es posible que él pretendiera incluir derechos más allá de los ya implícitos en la apelación a los derechos que los ciudadanos ostentan. El principio que abordamos más arriba -el derecho de $\mathrm{C}$ a convertirse en parte del contrato entre A y B- y la discusión más general sobre Freeman, podrían sugerir que está en juego un conjunto más amplio de derechos. En este punto quiero hacer tres observaciones. Primero, Freeman rechaza la posibilidad de contemplar una serie de derechos específicos asignados a los stakeholders. Su pragmatismo se lo impide. Escribe: "La 'teoría de los stakeholders' se puede subdividir en una serie de teorías, todas ellas con un 'núcleo normativo' enlazado de forma inextricable al modo en que las corporaciones debieran ser gobernadas, y a la manera en que los directivos debieran actuar. Por lo tanto, sería un error intentar definir más plenamente una teoría de los stakeholders" (Freeman, 2003: 413). Dado este compromiso con el pragmatismo, Freeman parece no poder rechazar la versión restringida de la teoría que yo sugiero en el presente artículo; pues resultaría ser uno de los tantos núcleos normativos posibles. En segundo lugar, a pesar de su pragmatismo, Freeman también describe su proyecto como "la articulación de una base moral más explícita para la idea de stakeholder" 
(Freeman, 2003: 415), y si tuviera en mente algún conjunto más amplio de derechos para los stakeholders, más allá de los garantizados por mi recurso a los principios de justicia, Freeman tendría que usar un argumento normativo. A falta de uno, la mejor manera de poder garantizarla -es decir, el modo más fuerte de teoría que podamos justificar-son los derechos y obligaciones de los stakeholders que se derivan de los principios de justicia. Tercero, el enfoque de los intereses de los stakeholders entendidos como ciudadanos puede generar el derecho de $\mathrm{C}$ a intervenir, al menos en una variante del caso descrito aquí (el del club de striptease). Por lo tanto, el modelo de teoría que aquí se articula es fuerte. Es más, de acuerdo con Norman Daniels, una sociedad que logre el objetivo de los principios rawlsianos "podría muy probablemente asegurar más igualdad para la gente que ninguna sociedad actual -inclusive los estados de bienestar más igualitarios", y como resultado, tal sociedad sería la más equitativa que pudiéramos imaginar (Daniels, 2003: 243). Por tanto, al margen del propósito de Freeman, no queda claro por qué deberíamos exigir (ni siquiera necesitar) algún conjunto de derechos más allá de los que se derivan de los principios.

Ejemplo: el asunto de los beneficios por maternidad y la asistencia a las mujeres que dejan su lugar de trabajo para dedicarse a criar a sus hijos abre interrogantes complejas en el terreno de la ética de la empresa. Existe aquí un buen número de opciones, las cuales se pueden defender de muchas maneras. Pero para Rawls la cuestión sería la de si necesitamos los beneficios por maternidad y la asistencia legal particular para las mujeres con el fin de proteger su acceso equitativo a las oportunidades sociales y económicas -como exige el segundo principio de justicia. Dicho acceso es un derecho fundamental de los ciudadanos, y no hay necesidad de recurrir a consideraciones más allá de los principios de justicia, o a una ética de las organizaciones. Volveré a este ejemplo en mi discusión en torno al pluralismo más adelante.

Otro ejemplo: el artículo de Hsieh (2005) sobre republicanismo laboral sigue esta lógica. La necesidad de democratizar el lugar de trabajo y la de subsidiar firmas manejadas por los trabajadores, ambas se basan a su juicio en los derechos fundamentales de los ciudadanos, tal y como se articulan en los principios de justicia. De 
esta manera, podríamos considerar que la línea de pensamiento más general que se defiende en el presente ensayo es un apoyo al método de Hsieh, es decir, su opción por los principios de justicia para fundamentar ese republicanismo laboral, antes que recurrir a algún conjunto de principios morales.

Otros ejemplos podrían ser:

- el requisito del salario mínimo (la falta de un ingreso mínimo restringiría injustamente los bienes esenciales de una persona, y aunque esto puede tratarse en el nivel institucional con programas como el Earned Income Tax Credit, los negocios que sobreviven pagando únicamente salarios sub-estándar podrían ser los que la sociedad rechazara, o no: los legisladores podrían determinar que la mejor forma de atender los intereses de los ciudadanos es no poniendo restricciones sobre salarios);

- las regulaciones medioambientales que tratan de forma adecuada las necesidades relacionadas con la sostenibilidad (el acceso a un entorno seguro y al mundo natural son bienes esenciales, y una sociedad que se tome en serio la "idea de sociedad como un sistema equitativo de cooperación social con el paso del tiempo de una generación a la siguiente" (Justicia como equidad §2, la cursiva es mía) se plantearía la cuestión de la sostenibilidad medioambiental de forma muy diferente a como la trata nuestra sociedad);

- las políticas de inmigración (los legisladores deberían abordar el tema de los derechos y privilegios laborales de los no ciudadanos, considerando tanto los intereses de los ciudadanos como los derechos humanos);

- protecciones para las negociaciones sindicales o de convenio (necesarias, quizás, para impedir la concentración excesiva de poder político y económico, como mencioné más arriba).

Podríamos continuar la lista. La idea general es que los principios de justicia proporcionan ya un conjunto bastante amplio de derechos y obligaciones en el ámbito de la actividad económica; estos derechos van más allá de aquellos mencionados típicamente como derechos humanos; estas obligaciones afectan a los directivos y a los negocios; no obstante, se tratan y se protegen desde un nivel institucional. Y en caso de que la estructura básica sea inadecuada, si los intereses de los ciudadanos no se ven protegidos, entonces la 
sociedad -no sólo los negocios sino la sociedad en su totalidad- no puede ser equitativa.

\section{Segunda parte: Libertad, pluralismo y el enfoque de los Mercados Morales}

Mi aplicación de los principios de justicia a la teoría de los stakeholders depende de una distinción cuidadosa entre ciudadanos y agentes económicos. Y dicha distinción genera la siguiente interrogante: ¿qué derechos y obligaciones tienen los agentes económicos más allá de los que ya se les presupone por su condición de ciudadanos?

Diera la sensación de que las cuestiones sobre los derechos y obligaciones de los ciudadanos y los de los agentes económicos pudieran complementarse mutuamente: donde Rawls trata los derechos y obligaciones de los ciudadanos en contextos económicos, pareciera dejar un espacio abierto para teorizar aún más sobre la ética, tanto en el ámbito general de la actividad económica como en el más restringido del de las organizaciones. Sin embargo, la concepción política de justicia de Rawls nos da dos razonas para rechazar este tipo de compatibilidad: los derechos y obligaciones más allá de los ya presupuestos en los ciudadanos restringen de forma innecesaria la libertad de éstos, y el pluralismo sugiere que no puede haber consenso sobre una ética de la actividad económica. En lo que sigue, trataré estos dos puntos, los cuales sugieren una defensa del enfoque de Boatright sobre los Mercados Morales. La discusión genera tres cuestiones más técnicas que trataré en el Apéndice del presente ensayo.

\section{A. Más derechos y obligaciones adjuntas a la actividad económica violan la libertad de los ciudadanos}

Según Rawls, fuera de las obligaciones que se derivan de los principios de justicia y realizadas en la estructura básica o, dicho de otro modo, dentro de los límites establecidos por los principios mismos, los individuos - los ciudadanos- deberían ser libres para perseguir sus propios intereses, inclusive sus intereses como agentes económicos. 
Las asociaciones privadas se pueden formar y organizar en una multitud de maneras que promuevan los intereses individuales. Y dichas asociaciones deben ser toleradas en tanto en cuanto no violen los principios de justicia, a saber, siempre y cuando no atenten contra las leyes y normas plasmadas en la estructura básica. Rawls es explícito al respecto: "en el marco de la justicia de fondo establecida por la estructura básica, individuos y asociaciones pueden hacer lo que quieran mientras esté permitido por las normas de las instituciones" (Rawls, 2001: 50). Y un pasaje paralelo extraído de su Liberalismo político señala: "Llegamos por tanto a la idea de que los ciudadanos libres e iguales deben disfrutar de libertad para hacerse cargo de sus vidas, y se espera de cada uno de ellos que adapte su idea de lo bueno a su parte equitativa de bienes esenciales. La única restricción que afecta a los proyectos de vida es su compatibilidad con los principios públicos de justicia, y las reclamaciones se pueden proponer sólo para ciertos tipos de cosas (los bienes esenciales), y en las formas que especifican esos principios" (Rawls, 1993: 189-190, la cursiva es mía).

Así, incluso si -contrariamente a lo que se propone más abajo, a la posición de Rawls- pudiésemos garantizar el consenso social sobre derechos y obligaciones adicionales que se desprendan de la actividad económica, restricciones de este tipo llegarían a una limitación irrazonable de la libertad individual. (Para concretar este argumento aún más, yo podría reclamar el derecho a tener jornada laboral flexible; si se encontrara protegido en el nivel institucional o, de alguna manera, viniera impuesto, este supuesto derecho restringiría la capacidad del gerente de una firma a la hora de organizar los horarios laborales de la mejor manera según los objetivos de la organización; y dicha restricción no se justificaría porque el derecho en cuestión, el de tener jornada laboral flexible, no se deriva de los principios de justicia.) Aquí, "irrazonable" se usa en el sentido técnico que para Rawls tiene el término: una persona es razonable si se presta a aceptar principios equitativos de cooperación, incluso cuando éstos restrinjan su ventaja racional, es decir, de interés personal. En otras palabras, una persona es razonable si él o ella participa en el proceso que genera los principios de justicia; no se requiere nada más (véase 
Rawls, 2001: §2). Que haya más restricciones resulta ser irrazonable porque van más de las que un individuo aceptaría en virtud de su interés para garantizar principios equitativos de cooperación social. De este modo, y en breve, aquí la libertad para ir en busca de lo que cada uno entienda por bueno establece un límite superior en torno a la obligación social que se desprende de la actividad de los negocios. Esta libertad impide un conjunto excesivamente extenso de obligaciones sociales para los agentes económicos (individuos y negocios). ${ }^{5}$ Y tomando prestado un término de Donaldson y Dunfee (1999), podríamos decir que ambas, la actividad individual y la corporativa, tienen lugar en un ámbito libre de moral generado por los principios de justicia.

El asunto de la libertad sugiere un argumento directamente rawlsiano para la existencia de las corporaciones: mientras éstas no amenacen los principios de justicia, o en tanto que las amenazas a los principios sean tratadas mediante restricciones apropiadas $y$ obligaciones positivas, los individuos son libres de formar y participar en dichas organizaciones de la manera que crean conveniente. Esta línea de argumentación es similar a la defensa moral de las empresas comerciales realizada por Sollar (2002): si la mera existencia de las empresas comerciales requiere una defensa moral, es por esta línea que la encontramos en el contexto de la obra de Rawls. En un trabajo reciente, Bishop (2008) señala que las partes del contrato social considerarían como compatibles con los principios de justicia a las corporaciones con ánimo de lucro. Este argumento se basa en un segundo ejemplo de la posición original de Rawls, que Bishop confecciona para esa cuestión en particular. No obstante, su segundo contrato social resulta ser innecesario: los principios de justicia

\footnotetext{
Child y Marcoux (1999) argumentan que Freeman, al recurrir a Rawls -lo cual discutimos ya en la Primera parte- supone un número de dificultades internas. Este párrafo donde tratamos dicho recurso explicaba además por qué el segundo ejemplo de Freeman de la posición original para garantizar la teoría de los stakeholders en realidad entra en conflicto con la obra de Rawls: los ciudadanos razonables no están obligados a participar en contratos sociales más allá del que se usa para determinar los principios de justicia. Este argumento -por sí mismo- no demuestra que mi aplicación de Rawls sea mejor, ni tampoco nos da un motivo para rechazar la versión de Freeman de la fundamentación normativa de la teoría de los stakeholders. Pero quiero hacer notar este conflicto por la siguiente razón, y es que mi recurso a Rawls sugiere una conclusión muy diferente a la de Freeman: ambos aplicamos la obra de Rawls con el fin de proporcionarle a la teoría de los stakeholders una fundamentación normativa, sin embargo concluimos con respuestas diferentes; esa diferencia requiere una explicación: a mi juicio, Freeman utiliza la posición original de un modo que Rawls jamás pretendió, y que en realidad está en desacuerdo con la sustancia de los principios de justicia.
} 
cubren ya los asuntos económicos, y el derecho a formar asociaciones, incluyendo las corporaciones, ya viene garantizado por medio de la libertad de los individuos para perseguir sus propios intereses.

Otra aplicación de mi argumento sobre la libertad: la dirección agresiva, incluso implacable, de una firma en los límites de los principios de justicia es también coherente con la obra de Rawls (los pasajes citados al comienzo de esta sección aclaran este supuesto). Rawls tendría que permitir la reivindicación de Friedman (1970) de que el propósito de las corporaciones es el de atenerse a la ley y ganar dinero, porque Friedman concede que los negocios están constreñidos por leyes y normas. Lo cual resulta quizás algo sorprendente, pero en el marco de la obra de Rawls estas leyes, junto con las instituciones más generales circundando la actividad de los negocios, llevan a cabo los compromisos expresados en los principios de justicia -y por lo tanto tales leyes y normas impiden a los directivos maximizar los beneficios en un modo que conlleve violaciones de los derechos e intereses protegidos en la obra de Rawls. (Nótese lo siguiente: ni Friedman ni Rawls requieren que una firma sea administrada de forma que maximice el beneficio; ni tampoco pondrían objeciones en caso de que los dueños de la empresa desearan construir capital social mediante el pago de un salario más alto que el del promedio para los puestos de trabajo obrero o de manufacturación en un área económicamente deprimida.) Desde esta perspectiva (y quizás interpretándole de forma caritativa) Friedman se puede leer en clave de objeción a obligaciones adicionales que acompañen la actividad de los negocios, más allá de los establecidos por el contrato social, ya que estas obligaciones adicionales son -piensa él- restricciones arbitrarias de la libertad individual y también de la eficacia económica. Por tanto, desde la perspectiva rawlsiana la posición de Friedman es razonable (en el sentido técnico que para Rawls guarda el término).

Un punto más sobre la libertad: esta línea de pensamiento se aplica en el nivel institucional (nuevas obligaciones incluidas en la estructura básica violan la libertad), y también en el de las organizaciones individuales -ningún contrato local sería vinculante para los ciudadanos que no deseen participar en ellos. Con respecto 
a los contratos locales (para una organización individual), no hay nada en la obra de Rawls que impida a los grupos utilizar métodos contractuales para crear o regular internamente una organización, inclusive una corporación. Y nada impide tampoco a los individuos usar el razonamiento de estilo contractual para pensar sobre sus obligaciones con los otros en contextos económicos u otros escenarios organizacionales. Pero los ciudadanos no están obligados a participar en contratos sociales adicionales -en un contexto organizacional o en transacciones individuales- por la misma razón ya apuntada, a saber, que la participación en el contrato social agota las obligaciones sociales de la persona, que la participación agota los requisitos de Rawls para ser una persona razonable. Más aún, Rawls piensa que hay posibilidades limitadas para el acuerdo sobre nuevos contratos o, dicho de otra manera, que cualquier nuevo acuerdo sería local, no existen razones para reclamar en ese ámbito que todo se debería o podría aceptar. Esto último es consecuencia del pluralismo, el cual trataré en la siguiente sección.

B. El pluralismo sugiere que no puede darse un consenso sobre derechos y obligaciones más allá de los que se derivan de los principios de justicia (más allá de los derechos y obligaciones de los ciudadanos).

En Teoría de la justicia Rawls fundamenta los principios de justicia con una comprensión kantiana general del bien humano. Pero en los ensayos recogidos en su Liberalismo político, al igual que en Justicia como equidad, Rawls permite que en las democracias liberales modernas los ciudadanos sostengan una variedad de doctrinas morales comprehensivas, con diferentes (y posiblemente incompatibles) concepciones del bien. Como resultado, Rawls se ve forzado a reconstruir el argumento de los principios de justicia: dado el fenómeno del pluralismo de las doctrinas morales comprehensivas, él no puede seguir asumiendo que los ciudadanos comparten su idea particular del bien, por lo que no puede partir de esa concepción del bien para llegar a los principios de justicia. En cambio, Rawls sostiene que las partes del contrato social aceptan los principios de 
justicia sobre la base de un compromiso previo en torno a que las personas sean libres e iguales, y otro compromiso previo para hallar los principios de justicia que generarán un sistema equitativo de cooperación social. Él asume ambos compromisos como ya dados, como parte de la cultura política de fondo en las democracias liberales; su proyecto consiste en desarrollar lo que el primero de estos compromisos (libres e iguales) exige por nuestra parte, contando con el segundo de los compromisos para explicar el interés de las personas por la cooperación. La justicia como equidad es, por tanto, una concepción política de la justicia en la obra del último Rawls, "política" porque no necesita aceptar ninguna fundamentación moral particular o teoría del bien.

Las "cargas del juicio" explican por qué los ciudadanos no llegarán a un acuerdo en materia de doctrinas morales comprehensivas. Entre las cargas encontramos las siguientes: la compleja evidencia de que es difícil valorar y evaluar, los desacuerdos sobre el peso de dicha evidencia, la indeterminación a la hora de aplicar nuestros conceptos, y las diferentes respuestas debido a los requisitos normativos en conflicto (las cargas del juicio son enumeradas en Rawls, 1993: 54-58). Estos factores sugieren que las cargas generan un problema epistemológico: formar una doctrina moral comprehensiva sobre la base de la evidencia y de conceptos normativos implica mucha indeterminación y sub-determinación. Como resultado -así lo señala Rawls- los ciudadanos reflexivos pueden llegar a diferentes posiciones: "muchos de nuestros juicios más importantes se realizan bajo condiciones donde no se puede esperar que personas reflexivas en plenas facultades racionales, incluso tras un debate libre, puedan llegar todas ellas a la misma conclusión" (Rawls, 1993: 58). Dadas las cargas del juicio, el proyecto de Rawls es el de justificar la posibilidad del acuerdo sobre una concepción política del juicio. Tal acuerdo no está en absoluto asegurado. Dreben plantea la cuestión del siguiente modo: "Si disponemos, como es el caso ciertamente en el mundo moderno, de doctrinas comprehensivas opuestas, a las que se adhieren los miembros de la sociedad -esto es algo dado-, ¿es posible que dicha sociedad pueda ser considerada una democracia liberal constitucional?" (Dreben, 2003: 322-323). Pero podríamos 
enunciar la pregunta en unos términos más positivos: ¿cómo es posible una democracia liberal constitucional dado el pluralismo?

La respuesta de Rawls es más o menos esta: las partes del contrato social pueden aceptar los principios de justicia sobre la base de los dos compromisos mencionados dos párrafos más arriba, incluso aunque posean diferentes perspectivas morales comprehensivas. $\mathrm{O}$ dicho de otro modo, si estas partes aceptaran los principios de justicia sobre dicha base, entonces Rawls catalogaría al pluralismo de razonable. Haciendo énfasis en esto: fuera de los dos compromisos ya mencionados, los cuales encontramos plenamente expresados en los principios de justicia, Rawls no espera que se produzca un amplio acuerdo en torno a estas perspectivas morales comprehensivas. Pero los ciudadanos razonables reconocen las cargas del juicio; y al hacerlo, están reconociendo que otros mantendrán diferentes doctrinas comprehensivas; y por lo tanto, los ciudadanos sólo recurrirán a los principios de justicia (y no a otros principios morales) en su uso público de la razón -en el debate sobre y la justificación de aspectos de la estructura básica. (Nótese que Rawls define "razonable", en parte, con respecto a este reconocimiento; desde ninguna concepción independiente de lo razonable se discute el reconocimiento de las cargas.) Samuel Freeman lo expresa del siguiente modo: "Esto [las cargas del juicio] significa que hay ciertos tipos de razones y argumentos que deben ser sacados, por así decir, de la vida pública, incluso aunque sean verdaderos. Esto afecta a razones y argumentos basados exclusivamente en las diferentes concepciones religiosas, filosóficas y éticas de la gente, pues forman parte del motivo por el cual incluso la gente razonable y racional no pueda ponerse de acuerdo (Freeman, 2007: 317). Desde la concepción política, por tanto, los principios de justicia proporcionan el único punto de vista mutuamente aceptado para resolver reclamaciones en disputa sobre derechos y obligaciones.

Rawls contempla el pluralismo como un resultado positivo porque refleja el uso libre de la razón humana, lo cual es, a su juicio, algo obviamente bueno (aquí "bueno" se define en términos del compromiso de fondo para que los ciudadanos sean libres): "[Las diferentes doctrinas comprehensivas] no son simplemente la consecuencia de 
los intereses individuales y de clase, o de la tendencia comprensible de la gente a contemplar el mundo político desde un punto de vista limitado. En cambio, son en parte el fruto de la razón política libre en el marco de instituciones libres. Así, aunque las doctrinas históricas [es decir, consideradas desde un contexto social e histórico] no son por supuesto el fruto de la razón libre a solas, el hecho del pluralismo razonable no resulta ser una condición desafortunada de la vida humana... [si no más bien] el resultado inevitable de la razón humana libre" (Rawls, 1993: 37). Este pasaje sugiere más aún que las diferentes doctrinas morales y concepciones del bien son legítimas -algo que también se concluye de mi discusión sobre las cargas del juicio. Rawls hace explícita esta sugerencia en el siguiente pasaje: "Las diferentes concepciones del mundo pueden ser elaboradas de forma razonable desde distintos puntos de vista, por lo que la diversidad surge en parte de nuestras perspectivas diferenciadas. Resulta poco realista -o peor, suscita mutua sospecha y hostilidad-suponer que todas nuestras diferencias tienen por origen única y exclusivamente la ignorancia y la perversión, o las luchas de poder, estatus o lucro económico" (Rawls, 1993: 58). Más aún:

una comprensión compartida y sostenida en el tiempo de una doctrina comprehensiva religiosa, filosófica o moral sólo puede ser mantenida por el uso opresor del poder estatal. Si imaginamos la sociedad política como una comunidad unida al afirmar una y la misma doctrina comprehensiva, entonces ese uso opresor del poder estatal resulta necesario para la comunidad política. En la sociedad de la Edad Media, más o menos unida a la hora de afirmar la fe católica, la Inquisición no fue algo accidental: su supresión de la herejía fue necesaria para preservar esa creencia religiosa compartida. Creo que lo mismo se sostiene para cualquier doctrina filosófica y moral comprehensiva razonable, ya sea o no religiosa. Una sociedad unida en torno a una forma razonable de utilitarismo, o en torno al liberalismo razonable de Kant o Mill, requeriría asimismo las sanciones del poder estatal para permanecer así. Esto lo llamo el "hecho de la opresión" (Rawls, 1993: 37).

Por tanto, Rawls no discute que las doctrinas morales comprehensivas se apoyen con frecuencia en doctrinas religiosas, que dichas doctrinas religiosas se sitúen fuera del ámbito de la razón, y que las diferencias en cuanto a las doctrinas comprehensivas no 
puedan resolverse por medio de ésta. El asunto del pluralismo aplica directamente a doctrinas filosóficas tanto como a las religiosas. Pero a pesar de los pasajes aquí citados, y de su discusión sobre las cargas del juicio, Rawls no ofrece un argumento teórico; no niega la posibilidad de que diferentes concepciones del bien sean posibles y legítimas al mismo tiempo, pero tampoco brinda una versión teórica del relativismo. Para él la clave parece ser de naturaleza empírica: la falta de acuerdo en torno a las doctrinas morales comprehensivas es un hecho evidente. Para mis propósitos en el presente ensayo voy a considerar la siguiente concepción más restringida del pluralismo: cualesquiera que sean las posibilidades teóricas para resolver disputas entre doctrinas morales comprehensivas, posibilidades que Rawls no trata directamente, no habrá acuerdo entre los ciudadanos para todos los propósitos prácticos. De lo que se desprende que el pluralismo supone una limitación para lo que Rawls llama "posibilidad política factible" (Rawls, 2001: 4). Y de este modo el pluralismo imposibilitará el consenso sobre cuestiones morales (o, en el mejor de los casos, el consenso sería un producto temporal de factores inestables y contingentes), idea que deseo aplicar en la discusión sobre los derechos y obligaciones que acompañan a los agentes económicos.

Dado el pluralismo, no podemos esperar un consenso sobre tales derechos y obligaciones que acompañan la actividad económica. Dicho de otro modo, debido al pluralismo la sociedad democrática no es una comunidad en el sentido que Rawls entiende este término, refiriéndose a una "sociedad gobernada por una doctrina religiosa, filosófica o moral comprehensiva compartida" (Rawls, 1993: 42; un pasaje paralelo en Rawls, 2001: 3). Así pues, si Rawls está en lo cierto, no puede haber un consenso de la sociedad en torno a los principios o compromisos morales más allá de los principios de justicia y, por tanto, ninguna fundamentación compartida para las reclamaciones morales sobre derechos y obligaciones que acompañan a los agentes económicos.

Arriba utilicé el ejemplo de los beneficios por maternidad y la asistencia para las mujeres que abandonen el lugar de trabajo para criar a sus hijos. Allí argumenté que para Rawls la cuestión sería la de si se necesitan este tipo de beneficios para proteger el acceso equitativo de las mujeres a las oportunidades sociales y económicas. 
Expuse además que un acceso tal es un derecho fundamental para los ciudadanos, por lo que no hay necesidad de apelar a consideraciones más allá de los principios de justicia para garantizar los derechos de maternidad, no es necesario apelar a una ética en el ámbito de la actividad económica. Nótese aquí que tal apelación no sería capaz de proteger los derechos de maternidad -porque, junto con Rawls, no existen principios morales compartidos además, o al margen, de los principios de justicia, y por tanto no hay una base que permita establecer la pregunta sobre cuáles son las protecciones y obligaciones apropiadas en el ámbito de la actividad económica. Las personas podrían (y se les debería permitir) realizar reclamaciones morales en este ámbito, pero debido al pluralismo no podemos esperar que todas las personas acepten dichas reclamaciones. Así, este ejemplo apoya lo que queremos defender en esta sección, a saber, que no es posible una ética de la actividad económica.

Nótese además: Rawls diría que las reclamaciones morales individuales (realizadas sobre la base de doctrinas morales comprehensivas personales) no resultan ser un fundamento adecuado para una decisión sobre los derechos de maternidad. No deseamos que las cuestiones sobre tales derechos vengan establecidas por la concepción idiosincrática de la ética y la equidad perteneciente a una organización individual o a un directivo -ya que en tal caso se pondría en riesgo el acceso de las mujeres a las oportunidades económicas. Dicho de manera más abstracta: puesto que no vivimos en una comunidad en el sentido de Rawls, es demasiado peligroso dejar que individuos y organizaciones individuales decidan sobre las cuestiones fundamentales relacionadas con los derechos y oportunidades de los ciudadanos.

\section{Una defensa del enfoque del Mercado Moral.}

Podríamos resumir el material presentado en la anterior sección del siguiente modo. Rawls describe su obra comenzando por nuestro sentido intuitivo de equidad para entonces, a través del proceso de equilibrio reflexivo, llegar a una caracterización más precisa de lo que esa intuición exige de nosotros. Dicha caracterización especificará lo que se pueda considerar como equitativo en el contexto polí- 
tico (exactamente, aclarará lo que equivalen nuestros compromisos con ciudadanos libres e iguales). El acuerdo sobre esta cuestión más restringida de lo que sea considerado como equitativo en el ámbito político es posible gracias a un compromiso previo fundamental con personas libres e iguales, y gracias también a un compromiso previo para hallar principios de justicia que crearán un sistema equitativo de cooperación social. Sin embargo, y debido al pluralismo, no se dará un acuerdo en torno a cuestiones sobre lo que podamos considerar como equitativo en la esfera económica o en algún otro contexto local. Para estar seguros, Rawls mismo (que yo sepa) no se refiere explícitamente a este asunto, pero su versión del pluralismo sugiere que no puede haber un acuerdo general en torno a la equidad más allá del reflejado en los principios de justicia; defiendo más detalladamente esta línea de pensamiento en el Apéndice. Aquí lo que me interesa es recalcar lo siguiente: como resultado del pluralismo, las cuestiones acerca de la equidad en las organizaciones no vendrán establecidas de forma teórica, no podemos esperar generar un consenso en ejercicio o como un asunto de argumentación filosófica. Por el contrario, habrá una especie de mercado en el que las personas elegirán afiliarse con o trabajar para ciertas organizaciones, o no. A lo que se refiere Rawls con el uso libre de la razón humana producirá una cantidad cualquiera de organizaciones, erigidas con modelos de equidad opuestos, y los individuos serán libres de elegir dónde y cuándo participar. Esto podría parecer peligroso, en el sentido de que pareciera convertir a las personas en víctimas de fuerzas económicas y de la coerción. No obstante, los derechos fundamentales de las personas, en su calidad de ciudadanos, están protegidos en el sistema social general originado en la estructura básica.

Puede resultar que hoy por hoy no dispongamos de tal sistema, que carezcamos de protecciones adecuadas para los ciudadanos, lo cual nos conduce a dos opciones: actividad en la esfera política con el fin de lograr una sociedad más justa, o tratar en el sistema económico las cuestiones concernientes a la equidad.

La segunda podría en principio parecer más prometedora: al carecer de las protecciones proporcionadas por la estructura básica (es decir, por los principios de justicia), deberíamos trabajar en pos 
de una concepción de la equidad en el nivel de las organizaciones, una concepción de la equidad para los agentes económicos. Reich (2008: 168-169) sugiere que esta segunda línea de pensamiento subyace al trabajo sobre responsabilidad social corporativa, y nos ofrece una crítica con sustento en donde argumenta -en parte- que las presiones competitivas en el sistema económico se han intensificado y que, como resultado, no podemos esperar de las corporaciones una actuación responsable (véase también Doane, 2005). Por otra parte, si el planteamiento de Rawls sobre el pluralismo, o mi formulación más débil (es decir, si el pluralismo es un hecho de la vida en las democracias modernas, ya sea o no evitable teóricamente) resultan ser correctos, entonces no podemos esperar un consenso sobre la equidad más allá de los principios de justicia, por lo que debemos trabajar en el nivel político. Esta conclusión se concreta en el ejemplo de los derechos de maternidad. Ya que los argumentos propios de la ética de la empresa deberán apelar a los principios de justicia o -en aplicación al margen del contexto rawlsiano- a rasgos característicos de nuestro proceso democrático, el terreno práctico de la ética de la empresa debe ser el proceso político. Y las soluciones, al menos para los que pensamos que existen problemas fundamentales que necesitan ser solucionados, requerirán que se modifique el consenso político, o que se vuelvan a trazar los límites del contrato social (y esto incluye las expectativas sociales en asuntos que no son tema de leyes reales). El resultado será un nuevo consenso entrecruzado [overlapping consensus] (en la terminología de Rawls) para principios equitativos de justicia, o un nuevo consenso sobre la realización de esos principios en su aplicación en la actividad económica. Nuevos principios o su mejor realización mantendrán de forma más equitativa el sistema de cooperación social -donde equidad significa la realización de un compromiso con ciudadanos libres e iguales. Este enfoque cubre un vacío detectado por Marens (2007: 64): "En el transcurso de la última generación han sido pocos los especialistas en ética de la empresa que han recomendado cambios en el entorno legal, que sirvan como herramienta apropiada para elevar los estándares éticos o promover la justicia social" -donde la justicia social se extiende a la esfera económica. 
Aquí surge un riesgo: las corporaciones pueden apoderarse del sistema político (de hecho así ha sucedido). La obra de Reich que acabo de citar (Reich, 2008) expone el asunto, incluyendo una historia detallada de la economía estadounidense desde la Segunda Guerra mundial, y con una selección poderosa de ejemplos. Y debido a este riesgo -nuevamente- reivindicar ambas, la responsabilidad social corporativa y la ética de las organizaciones, podría parecer más prometedor que trabajar en pos del cambio institucional mediante el proceso político. Pero los dos argumentos de arriba son pertinentes en su planteamiento: primero, Reich señala que las presiones competitivas impiden a las empresas actuar de manera responsable a menos que sus acciones les proporcionen también algún beneficio $-y$ sobre esa condición abandonarán la responsabilidad social en el momento que les deje de reportar dicho beneficio. En segundo lugar, el pluralismo sugiere que no habrá consenso sobre qué acciones puedan ser consideradas como responsables, o suficientemente responsables. Por otro lado, Reich señala que hay algo fundamentalmente antidemocrático en la responsabilidad social corporativa: los ciudadanos son los que deberían determinar las obligaciones y responsabilidades que acompañan a la actividad económica; cederle esta decisión a las corporaciones deja a los ciudadanos a merced de la toma de decisiones corporativa no responsable. La única alternativa que nos queda en este caso es recuperar el proceso político.

La versión de la ética de la empresa que aquí se esboza es una especie de minimalismo, en el sentido de que asume los principios de justicia para expresar el consenso social sobre las restricciones y obligaciones que deberían acompañar la actividad económica. Al margen de una sociedad bien ordenada, cuando leyes, instituciones y normas sociopolíticas resultan ser inadecuadas (en comparación con los principios de justicia), podríamos no obstante utilizar los principios para desarrollar lo que las restricciones y obligaciones deberían ser. Podríamos hacer reclamaciones morales sobre restricciones y obligaciones adicionales más allá de la esfera de los principios de justicia, pero en la obra de Rawls no se encuentra fundamento alguno para tales reclamaciones, y su compromiso con el pluralismo razonable exige su rechazo de esas reclamaciones adicionales. 
A pesar de ser minimalistas en este sentido, las obligaciones sociales que acompañan a la actividad económica -esto es, las exigencias de justicia en el proyecto de Rawls-resultan ser de gran alcance incluso en la esfera económica y, como hemos notado, estas obligaciones abordan directamente la amenaza social de la actividad económica.

Si las tomamos juntas, tanto mi consideración del lugar de la actividad práctica en la ética de la empresa como la concepción de la teoría de los stakeholders presentada más arriba, ambas ideas nos ayudarán a desarrollar la sugerencia de Boatright (Boatright, 1999), a saber, que la ética de la empresa se debe centrar más bien en los Mercados Morales y no en los Directivos Morales. Concluyo trazando la conexión entre mi trabajo y el de Boatright, aunque debo hacer notar lo siguiente: la discusión que sigue a continuación es sólo un comienzo del desarrollo de las implicaciones más generales de la obra de Rawls en la ética de la empresa en lo que respecta al proyecto de Boatright. Aún queda mucho por decir sobre la reorientación del argumento y el resultado práctico.

Según Boatright, la ética de la empresa está organizada en torno al modelo del Directivo Moral. Dicho modelo considera a las organizaciones empresariales como la unidad fundamental de análisis, y aspira a "introducir la ética en la toma de decisiones corporativa, lo que equivale a decir [en el interior] de los procesos mentales de los directivos" (Boatright, 1999: 585). Existe un "consenso aproximado" sobre este enfoque, pero a juicio de Boatright es inadecuado por cuatro razones (Boatright, 1999: 584). Primero, no parece estar funcionando (su artículo fue escrito antes del escándalo Enron y antes de la actual crisis económica). Segundo, las personas participan en negocios con motivaciones económicas, interesadas en el lucro personal; las consideraciones éticas entran en conflicto con la "lógica" de esta actividad (Boatright, 1999: 586). Tercero, la interacción económica se encuentra altamente reglamentada por roles individuales, jerarquías organizacionales, marcos legales y exigencias contractuales -en esta estructura: a) queda poco espacio para la integración de las consideraciones éticas por parte de los directivos, y b) aquí la discreción conducirá a conflictos entre puntos de vista individuales y exigencias contractuales. Cuarto, el modelo del Di- 
rectivo Moral se aplica a los altos directivos de las organizaciones, los que deben tomar las decisiones al más alto nivel, y esto ignora la amplia gama de agentes económicos.

La primera y la cuarta poseen una fuerza limitada. Sobre la primera crítica, decir que siempre habrá escándalos y ladrones. Y con la información disponible se podría formular exactamente la conclusión opuesta, a saber, que la inmensa mayoría de la gente de negocios integran consideraciones éticas en la actividad económica. Como resultado, la gran mayoría de los agentes económicos operan de forma moralmente aceptable. Sólo escuchamos hablar de las excepciones. Pero incluso con esta reinterpretación de la información, todavía no queda claro si se le puede atribuir este tipo de comportamiento a la ética de la empresa; es probable que el mercado demande una actividad moralmente aceptable, y que personas de poca confianza quedarán excluidas de futuras transacciones. La cuarta crítica de Boatright se puede abordar desde el modelo del Directivo Moral: la ética de la empresa, interpretada de forma más amplia, podría tratar las consideraciones éticas en la actividad económica; esto sólo requiere de un cambio de enfoque más allá de la alta dirección.

La segunda de las críticas también tiene un alcance limitado: incluso si participamos en negocios como agentes económicos interesados en el lucro personal, somos a la vez ciudadanos con intereses en el bien social $-\mathrm{y}$ como personas podríamos operar con (e intentar integrar) un conjunto amplio de intereses, incluso si dichos intereses entran en conflicto. El libro Supercapitalismo de Reich que acabamos de citar ofrece un poderoso análisis de estas situaciones dilemáticas, en las que los intereses como consumidores y como ciudadanos impulsan a las personas en direcciones opuestas.

Sin embargo, la tercera crítica de Boatright sí tiene un peso considerable: si él está en lo cierto, "la responsabilidad individual aparece en escena al comienzo, en el momento en que creamos roles y nos comprometemos con ellos. Una vez que hemos asumido esos roles la responsabilidad individual tiene un alcance limitado" (Boatright, 1999: 587) -de ese modo, la habilidad de los directivos para incorporar consideraciones éticas en su toma de decisiones es limitada 
y, por lo tanto, la ética de la empresa tiene pocas posibilidades de desarrollarse en el modelo del Directivo Moral.

El material presentado en las dos secciones anteriores le brinda a Boatright un quinto argumento contra el modelo del Directivo Moral: el pluralismo sugiere que no puede haber un consenso sobre derechos y obligaciones que acompañen a la actividad económica, más allá de los que se derivan de los principios de justicia, por lo que no podemos esperar que se dé un acuerdo sobre las reclamaciones morales en el ámbito de la toma de decisiones por parte de los directivos (sección B); por otra parte, ni siquiera existe una idea compartida acerca de lo que deba considerarse como equitativo en el nivel de las organizaciones particulares y de las transacciones económicas individuales (lo señalamos al comienzo de esta sección); y podemos hacer reclamaciones morales en el ámbito de la toma de decisiones de los directivos, pero las restricciones que acompañen a la actividad económica más allá de las ya institucionalizadas en la estructura básica violarían la libertad de los ciudadanos (sección A).

La alternativa propuesta por Boatright, el modelo de Mercados Morales, "reparte la responsabilidad entre todos nosotros para mejorar el sistema empresarial. Esto es, para crear mercados más eficientes, a la par que regulaciones más eficientes" (Boatright, 1999: 586). Pero su ensayo es de algún modo programático: el modelo de Mercado Moral "favorece los modelos formales de control social y un enfoque contractual a la cuestión de la regulación" (Boatright, 1999: 589); no obstante, no queda claro cuál sea la justificación filosófica para que se dé dicho control, y el marco institucional de esa regulación podría tener múltiples formas. El material concerniente a la teoría de los stakeholders, presentado en la Primera parte del presente ensayo, ofrece un modo de concretar aún más la propuesta de Boatright: el objetivo es situar los mercados en el contexto general de una sociedad justa, en el contexto de las instituciones sociales y políticas que protegen los intereses de los ciudadanos en el contexto económico. Dicho contexto institucional general -la estructura básica (no las instituciones empresariales) - proporciona las constricciones (el "control social") y la regulación que necesitamos a juicio de Boatright. Más específicamente, el contexto institucional 
general proporciona la estructura legal y regulatoria necesaria para limitar el alcance de la toma de decisiones gerencial -porque los principios de justicia "apartarían de los directivos [usando la formulación de Boatright] áreas de toma de decisiones, y las pondrían en otras manos" (Boatright, 1999: 588). En concreto, los principios depositarían estas decisiones en manos de los ciudadanos, para que decidan cómo deberían constreñirse las transacciones del mercado. El objetivo, entonces, no es exactamente tener mercados morales sino una sociedad equitativa, la cual requiere que se sitúen límites en torno al mercado. En otras palabras, la moralidad del mercado se mide y se lleva a cabo en el sistema social en su conjunto, del cual forma parte el mercado.

Smith (2005) ofrece tres críticas al enfoque de los Mercados Morales de Boatright. A continuación, deseo resumir brevemente esas críticas y mostrar cómo el marco teórico desarrollado en nuestro ensayo -y utilizado para concretar aún más la propuesta de Boatright- constituye una respuesta a Smith. En primer lugar, Smith señala que las consideraciones morales no se pueden reducir única y exclusivamente al mercado; cualquier fundamento normativo para la regulación de los mercados es, al mismo tiempo, un asunto moral a tener en cuenta en la toma de decisiones gerencial: "cualquier protección legal para los stakeholders debe a la vez proporcionar razones para que los directivos asuman responsabilidades morales paralelas" (Smith, 2005: 138). Pero en contra de lo que argumenta Smith, la obra de Rawls muestra por qué existe aquí una separación: los ciudadanos pueden llegar a acuerdos sobre los principios de justicia que establezcan límites en torno a la actividad económica, pero dados esos límites, o dentro de ellos, los ciudadanos permiten que los individuos -inclusive los directivos- sean libres de participar en la actividad económica sin constricciones (adicionales). De esto modo, no existe un conjunto de obligaciones morales que los directivos deban asumir más allá del conjunto de obligaciones que ya asumen como ciudadanos.

El segundo argumento de Smith es una variante del primero: si concebimos el ámbito de los negocios y la empresa como un ámbito moral, o como uno en el que las consideraciones morales no tengan lugar, ¿por qué habríamos de regularlo, y cómo se sustentarían 
tales regulaciones? ¿Por qué debería darse una reforma regulatoria progresiva si los propósitos morales que subyacen a la regulación son considerados contrarios a la ética por la misma institución objeto de tal regulación?" (Smith, 2005: 139). Nuevamente, la obra de Rawls nos ayuda en este punto: aceptamos restricciones en nuestra actividad como agentes económicos debido a nuestro interés -como ciudadanos- por la equidad en la sociedad.

Tomadas en consideración ambas respuestas a Smith que acabamos de trazar, éstas muestran lo siguiente: podemos distinguir por un lado la motivación económico-gerencial, y por otro los intereses de los ciudadanos por la equidad (aunque, para ser justos con Smith, algunos han criticado a Rawls en este punto: véase Cohen, 2000). Dada esta distinción, podemos abordar los intereses de los ciudadanos sin tener que tratar al mismo tiempo la motivación económico-gerencial. Pude responder así porque fundamento los derechos de los stakeholders en los intereses sociales de los ciudadanos (no está claro si dicha respuesta está disponible para Boatright sin mi especificación del punto de vista del Directivo Moral en términos rawlsianos).

El tercer argumento de Smith nos genera cierta dificultad y supone una mayor amenaza para la propuesta de Boatright del modo en que yo la desarrollo: Smith señala que siempre habrá vacíos en el marco legal y regulatorio en torno al mercado, y que sólo la gerencia moralmente responsable identificará esos vacíos y anticipará la conducta indebida. Al comienzo de esta sección sugerí que las empresas competirán por clientes, proveedores, trabajadores y accionistas -en el sentido de que competirán por los stakeholders, y las empresas con reputación de poseer la mejor conducta o la más transparente tendrán más posibilidades de ser exitosas ${ }^{6}$. Los directivos tendrán por tanto una motivación empresarial a la hora de identificar los vacíos legal-regulatorios y evitar la conducta indebida. Esa sugerencia -la de que el mercado puede proporcionar los límites que la regulación

6 Nótese aquí que las empresas con reputación de ser las que más beneficios obtienen pueden también tener éxito. Más que culpar a los directivos inmorales en el escándalo Enron, podríamos apuntar igual de fácil a los inversores ávidos de lucro, y a los analistas del mercado de valores que no se tomaron la molestia de prestar atención al estado financiero; la firma se descompuso cuando los analistas comenzaron a observar su estado financiero, no se necesitó ninguna nueva información. 
no puede- es compatible con otro de los argumentos de Smith, a saber, que la confianza y la autorregulación son menos costosas para las empresas que la regulación externa (véase Smith, 2005: 140). Sin embargo, Smith rechazaría mi sugerencia: el mercado no es lo suficiente competitivo, y por tal motivo debemos contar con la consideración moral de los directivos: "Una falta de competitividad en los mercados y una baja respuesta en el sistema legal y político son condiciones de fondo que justifican (desde la perspectiva de los stakeholders) el incremento de la responsabilidad gerencial como condición razonable para el consenso" (Smith, 2005: 137). Por otra parte, "no está claro que los stakeholders se embarcarían en un contrato sin la seguridad de que los directivos ejerzan por su parte la discreción" (Smith, 2005: 137).

En este punto, Rawls podría observar (de nuevo) que no podemos esperar un consenso en el ámbito de la perspectiva del Directivo Moral, y que por esta razón debemos contar con la regulación generada sobre la base del consenso en el marco político. Por otra parte, yendo más allá de la obra de Rawls, no es razonable esperar que el proceso de formación de dicha regulación se complete en algún punto: las empresas y los mercados están constantemente evolucionando, razón por la cual la regulación y los límites también deben evolucionar. Éste podría ser un proceso desordenado; probablemente implicará ensayo y error -es decir, escándalo y abuso, y después su corrección. De manera que los escándalos y su evolución reflejan el proceso desordenado, empírico, de ensayo-error, y no un problema fundamental del enfoque de los Mercados Morales. Esta afirmación se puede extender: cuando Smith señala -en defensa del modelo del Directivo Moral- que necesitamos "introducir la ética en la toma de decisiones corporativa, lo que equivale a decir [en el interior de] los procesos mentales de los directivos”, ¿qué es lo que quiere decir exactamente? Smith cita a Enron como un ejemplo. Supongamos con Smith que la dirección de Enron se hubiera aprovechado de los vacíos en los estándares contables, y que deliberadamente infló el valor de los ingresos esperados de la firma. Por lo tanto, la dirección de Enron habría operado fuera de los estándares morales aceptables. ¿Cómo propone Smith "introducir la ética en la toma de decisiones corporativa” para el caso de Enron? ¿Cómo nos protegerá o nos hará 
más seguros esta maniobra? Desde la perspectiva de Rawls, y junto con Boatright, debemos -en cambio- responsabilizarnos y crear un sistema social que proteja de la mejor manera posible los derechos e intereses de los ciudadanos.

\section{Apéndice: Ética de las organizaciones, concepción rawlsiana de equidad y el "principio de equidad" de Rawls.}

En esta sección final abordo tres cuestiones más técnicas generadas por mi aplicación de la obra de Rawls en el contexto de la ética de la empresa y, en particular, me centro en el trabajo de Phillips y Margolis sobre la ética de las organizaciones.

\section{A. Phillips y Margolis sugieren que la filosofía política no puede ocuparse de cuestiones concernientes a las or- ganizaciones.}

Phillips y Margolis (Phillips y Margolis, 1999) también realizan la distinción entre ciudadanos y agentes económicos, aunque usan una terminología algo diferente. En su caracterización, la filosofía moral se ocupa de los deberes, los derechos y las obligaciones que tenemos como seres humanos, y la filosofía política se interesa por los derechos y las obligaciones adicionales que acompañan al ciudadano. Dada esta distinción, afirman, para poder dar sentido tanto a los derechos y obligaciones adicionales que acompañan al "poder que ejercen los directivos en las organizaciones" (Phillips y Margolis, 1999: 620), como a "la importancia fundamental de las organizaciones” (Phillips y Margolis, 1999: 621), necesitaremos un paradigma teórico adicional, una ética de las organizaciones.

Ellos señalan en este punto que "tanto la teoría política clásica como la moralidad individual resultan inadecuadas para abordar los problemas morales que surgen en el contexto de la corporación moderna" (Phillips y Margolis, 1999: 620) -bajo el rubro de "teoría política clásica” queda también incluida la obra de Rawls. (El encabezado de la sección más abajo, en la p. 621, enfatiza este punto: "La insuficiencia de la teoría política y la filosofía moral", la cursiva 
es mía.) Este reclamo negativo tiene como objetivo motivar y aclarar el terreno para su trabajo sobre la ética de las organizaciones. Hartman (2001) ofrece una respuesta sistemática a la crítica general de Phillips y Margolis a la filosofía política y moral en la ética de la empresa. Pero Phillips y Margolis tienen razón en parte con respecto a Rawls: él no aborda la pregunta de cómo los beneficios de las actividades económicas particulares deberían distribuirse (en una anterior sección expliqué por qué no puede abordarla, y más adelante proporciono más información al respecto). De forma más general, Phillips y Margolis muestran -correctamente- por qué la versión rawlsiana de justicia política no puede llevarse al terreno de las organizaciones (por ejemplo, la participación en la sociedad crea un conjunto de obligaciones involuntarias, coercitivas, pero participar en organizaciones es algo voluntario, por lo que las obligaciones coercitivas no resultan apropiadas). Dicho esto, el reclamo negativo de Phillips y Margolis es demasiado fuerte: desde el momento en que la actividad económica afecta la distribución de los recursos sociales en el nivel sistémico, y en tanto en cuanto la actividad económica afecta los derechos y oportunidades de los ciudadanos, la sustancia de la obra de Rawls se ve aplicada directamente en el ámbito de la actividad económica y, por lo tanto, directamente en la ética de la empresa -aunque su obra no aborde la cuestión específica que ambos autores preguntan sobre equidad y obligación que acompaña a los directivos, o que está conectada con el lugar de las organizaciones en la sociedad. De hecho, en la Primera parte señalé que los derechos y obligaciones que acompañan a los ciudadanos representan el fundamento para la teoría de los stakeholders. Pero esta respuesta a Phillips y Margolis plantea nuevamente la pregunta citada al comienzo de la Segunda parte, a saber: ¿qué podemos decir acerca de la ética de la actividad económica -en el espacio abierto por los derechos y obligaciones de los ciudadanos?

\section{B. Phillips y Margolis apelan a Rawls para defender su trabajo de la ética de las organizaciones.}

Ambos autores sugieren un principio esencial de equidad para los stakeholders: que "los beneficios que se desprenden de un esfuerzo 
económico conjunto conllevan ciertas obligaciones, y la contribución al esfuerzo brinda ciertos derechos" (Phillips y Margolis, 1999: 629). Rawls estaría de acuerdo con esta afirmación en el nivel de la sociedad, pero no en el nivel de las organizaciones particulares o transacciones particulares. Este punto es una aplicación del material al comienzo de la Segunda parte, sección B: debido al pluralismo no se dará un consenso general en torno a cuestiones sobre lo que debemos considerar equitativo en la esfera económica, o en algún otro contexto local.

Pero Phillips (2003: 58) reformula la afirmación de que los stakeholders organizacionales se deberían beneficiar en proporción a sus contribuciones a la organización, y se apoya para ello en la obra de Rawls: "Si buscamos una justificación más profunda para [este] principio de la equidad en los stakeholders, entonces la justicia como equidad de Rawls proporciona dicha justificación. El principio de equidad en los stakeholders es una elaboración y expansión de la teoría de Rawls, y representa la concepción de asociación privada más consistente con un marco rawlsiano" (Phillips, 2003: 109). La afirmación es restringida: el principio de Phillips muestra que la actividad económica genera obligaciones entre los stakeholders, una obligación para distribuir equitativamente el beneficio de la colaboración, pero no se diseñó para decir cuáles son esas obligaciones (es decir, lo que se considera equitativo en este contexto). Esta apelación a Rawls sugiere que existe alguna base en su obra para una ética de la actividad económica, y si esto es correcto, entonces la línea de argumentación presentada en este ensayo - mi razonamiento de que Rawls rechazaría cualquier afirmación sobre derechos y obligaciones que acompañen la actividad económica- estaría equivocada.

La equidad es un término técnico en la obra de Rawls: como se contempló más arriba, la sociedad (un sistema de cooperación social) es equitativa si es recíproca, y los principios de justicia especifican lo que se considera como recíproco (véase Rawls, 2001: §2.3). Por tanto, los ciudadanos son los que definen lo que consideran por equitativo cuando aceptan los principios de justicia. Para estar seguros, Rawls señala que en su obra se explicitan nuestras intuiciones sobre la equidad, y se compatibilizan dichas intuiciones con nuestro compromiso con la libertad. Pero nuevamente el pluralismo limita 
la aplicación de esas intuiciones: los ciudadanos tendrán concepciones de la equidad diferentes y posiblemente rivales; los ciudadanos son razonables si llegan a un acuerdo sobre los principios de justicia que definen la equidad para un sistema de cooperación social; pero no cabe esperar el logro de un acuerdo más allá de aquél, lo que significa que no habrá un consenso general sobre cómo esas intuiciones se apliquen en el nivel de las organizaciones. (El "principio de equidad" de Rawls no ayudará aquí; éste será tratado en la siguiente sección.) De este modo, no queda claro cómo evaluar si una transacción o acuerdo económico son justos, o si una organización es cooperativa -si nos basamos en Rawls- porque no está claro lo que signifiquen equitativo y cooperativo en esos contextos. Y por lo tanto la sustancia de la obra de Rawls no puede desempeñar la labor que requiere Phillips: no ofrece una concepción de equidad que se pueda aplicar en el contexto de las organizaciones. Nos queda el mercado de posibilidades descrito más arriba, donde es imposible señalar cuál de ellas sea mejor o peor.

Además, los procedimientos rawlsianos tampoco ayudarán a Phillips: incluso si intentáramos usar el concepto de equidad de Rawls en una organización empresarial, Rawls afirma que deberíamos aceptar su idea particular de equidad sobre la base de la posición original. Pero ésta no se aplica en el marco de las organizaciones, por lo que no encontramos un argumento rawlsiano para un concepto de equidad en una organización empresarial (el propio Phillips nos proporciona un razonamiento convincente de por qué la posición original no se puede aplicar en una organización; véase Phillips, 2003: capítulo 3, y también Phillips y Margolis, 1999).

Por tanto, no hay modo de adaptar e incorporar el contenido o estructura argumentativa de la obra de Rawls a una ética de las organizaciones. Para ser claros: lo que aquí defiendo es la idea de que la obra de Rawls no sustentará la versión de Phillips sobre qué deba considerarse como equitativo o cooperativo en una organización. El desafío entonces está del lado de Phillips, quien ahora tiene que proporcionar una fundamentación alternativa para una ética organizacional que sea relevante tanto para directivos como para los demás miembros de la organización. Tal fundamentación tendrá que 
considerar las preocupaciones de Rawls sobre el pluralismo. O se podría proseguir con la estrategia propuesta en la Primera parte, y de ese modo aproximarse a la ética de las organizaciones en términos de los derechos de los ciudadanos en el contexto organizacional.

\section{Pero, ¿qué sucede con el principio de equidad de Rawls y su discurso sobre los deberes naturales? ¿No ser- virían para apoyar la idea de una ética en el ámbito de la actividad económica?}

En primer lugar, Teoría de la justicia (Rawls, 1999a: §18) se ocupa del principio de equidad para individuos, y este principio pareciera que podría sostener alguna concepción ética para individuos que participan en transacciones económicas. No obstante, en el contexto del libro de Rawls, este principio sólo requiere que los individuos actúen movidos por los compromisos que asumen: el principio de equidad explica (en el razonamiento de Rawls, 1999a) el motivo de por qué los ciudadanos están obligados a actuar según los principios de justicia tras aceptarlos, y por qué están obligados a tomar acciones sobre otras obligaciones que han asumido. Así se explica que "todas las obligaciones surjan del principio de equidad" (Rawls, 1999a: 301) -no porque ese principio sea de algún modo previo a los principios de justicia, ni tampoco porque ofrezca una concepción sustantiva de equidad, la cual termine de precisarse en los principios de justicia. El principio de equidad, por tanto, no proporciona ninguna orientación en absoluto sobre lo que deba considerarse como equitativo o cooperativo en una organización, o entre los agentes económicos, más allá de un requisito para hacerse cargo de los compromisos que realizamos. Así, por ejemplo, el principio no exige nada semejante al requisito de Phillips donde la participación en esfuerzos conjuntos brinda ciertos derechos, ni tampoco articula alguna otra concepción sustantiva de equidad. Este principio dejará de asumir un rol en la reconceptualización que tiene lugar en Liberalismo político, pero incluso en el contexto de Teoría de la justicia es incapaz de sostener una posición como la de Phillips. 
En segundo lugar, Rawls (Rawls, 1999a: §19) habla de deberes naturales; los ejemplos que proporciona son los siguientes: "ayudar a otra persona cuando está necesitada o en peligro, siempre y cuando ello no suponga un riesgo excesivo para nuestra integridad; y el deber de no infligir sufrimiento innecesario”, y más importante aún el deber de justicia, "apoyar y acatar las instituciones justas que existan y aplicarlas a nosotros mismos". Samuel Freeman (2007) sugiere que estos deberes naturales impondrán constricciones en torno a la actividad económica:

Rawls reconoce que la gente elegirá en el terreno económico motivada a menudo por razones egoístas. Pero asume que en una sociedad bien ordenada de justicia como equidad, donde los principios de justicia sean efectivos, y todos estén motivados por su sentido de justicia para cumplir y acatar, no podrán existir 'piratas' capitalistas de altos vuelos que busquen explotar a la gente, o jugar con el sistema de tal modo que beneficie máximamente a la gente con actitudes adquisitivas. Pues un sentido de justicia involucra un deseo de acatar los 'deberes naturales' de justicia, el respeto y la ayuda mutuas, etc. (Freeman, 2007: 122-123; Freeman cita a Rawls, 1999a: $\S \$ 18,19,51$ y 52.)

Si Freeman está en lo cierto, entonces existe en la obra de Rawls, en particular en los deberes naturales, alguna fundamentación para una ética en el ámbito de la actividad económica.

Pero en Teoría de la justicia estos deberes naturales se derivan del "concepto de lo correcto" -esto queda más claro en el diagrama presentado por Rawls en la p. 94 de dicho trabajo- el cual no juega ningún papel en la concepción política de justicia como equidad. Y no hay ideas compartidas sobre lo correcto o lo bueno en la reconceptualización rawlsiana de la justicia en términos políticos, después de la transición que supone Liberalismo político. Como resultado, no hay una fundamentación compartida para los deberes naturales, e incluso si tuviera sentido hablar de derechos naturales sin una fundamentación moral, tales deberes habría que interpretarlos en términos políticos. Esto mismo sirve para el principio de equidad: dicho principio -en el contexto de Teoría de la justicia- también se deriva de la idea de lo correcto, pero como esa idea no juega papel alguno en su última obra, el principio no puede desempeñar ningún 
rol cuando Rawls reconstruye el concepto de justicia como equidad en términos políticos?

Para ver cómo se pueden interpretar los deberes naturales en el contexto de los principios de justicia, consideremos el deber de la ayuda mutua. Teoría de la justicia lo presenta como un deber moral que sobresale por fuera de las relaciones políticas y de los principios de justicia (quizás sea previo a éstos). Rawls escribe: "Este es el deber que nos indica el respeto que se nos presupone como seres morales, es decir, seres con un sentido de la justicia y con una concepción del bien... El respeto mutuo se muestra de diferentes formas: en nuestra disposición a contemplar la situación de los otros desde su punto de vista, desde la perspectiva de sus concepciones del bien; y en nuestro estar preparados para dar explicaciones por nuestras acciones cada vez que los intereses de otras personas se vean materialmente afectados" (Rawls, 1999a: 297). No obstante, en la concepción política este deber se plasma -se agota- en nuestra aceptación de los principios de justicia. Al aceptar unos principios que otros también podrían aceptar si están motivados para hallar principios compartidos de justicia, muestro una disposición a contemplar situaciones desde puntos de vista ajenos al mío; al constreñir mis actos de forma que se atengan a los principios, muestro mi disposición a asumir esta perspectiva compartida; y al justificar mis actos en términos de los principios de justicia muestro mi disposición a dar explicaciones por mis actos cuando éstos afecten a los demás. La misma línea de pensamiento se aplica a los otros deberes naturales, incluido el deber de civismo que Rawls plantea en Liberalismo político (Rawls, 1993: 217) y, como resultado, los deberes naturales no pueden proporcionar una fundamentación para las constricciones sobre la actividad económica, o para derechos y obligaciones al margen de los ya su-

\footnotetext{
Nótese también: el principio de equidad ya no resulta ser necesario -tras Teoría de la justicia-por dos razones. Primero, el deber de seguir los principios que se aceptan queda conectado a lo que significa para una persona ser razonable, por tanto, ya no lo necesitamos en este sentido. Segundo, Rawls llega a pensar en términos de dos contratos sociales: elegimos los principios de justicia en la posición original, pero el argumento sobre las tensiones del compromiso dice que también los aceptaríamos en la práctica, sin las constricciones de la posición original. Por tanto, el segundo contrato elimina el problema de los oportunistas [free riders]. Esta cuestión de los dos contratos es analizada por Samuel Freeman en su introducción al The Cambridge Companion to Rawls (Freeman, 2003: 21), aunque no hace la conexión que yo presento aquí de mostrar que el principio de equidad ya no es necesario debido a este segundo contrato.
} 
puestos en los principios de justicia. Otro modo de formular nuestra afirmación general en este punto: podemos mantener una doctrina moral comprehensiva que no incluya deberes o derechos naturales de ningún tipo, por lo que dichos deberes y derechos no jugarían papel alguno en la obra de Rawls $\mathbf{C}$ 


\section{Referencias}

Bishop, J. D., 2008, "For-Profit Corporations in a Just Society", en: Business Ethics Quarterly, Vol. 18, No. 2, pp. 191-212.

Boatright, J. R., 1999, "Does Business Ethics Rest on a Mistake?", en: Business Ethics Quarterly, Vol. 9, No. 4, pp. 583-591.

Child, J. W. - Marcoux, A. M., 1999, "Freeman and Evan: Stakeholder Theory in the Original Position", en: Business Ethics Quarterly, Vol. 9, No. 2, pp. 207-223.

Cohen, G. A., 2000, If You're an Egalitarian, How Come You're So Rich? Cambridge: Harvard University Press.

Daniels, N., 2003, "Democratic Equality: Rawl's Complex Egalitarianism", en: S. Freeman (ed.) The Cambridge Companion to Rawls. Nueva York: Cambridge University Press.

Doane, D., 2005, "The Myth of CSR: The Problem with Assuming the Companies Can Do Well While also Doing Good is that Markets Don't Really Work that Way", en: Stanford Social Innovation Review (Fall issue), pp. 22-29.

Donaldson, T. - Dunfee, T. W., 1999, Ties that Bind: A Social Contracts Approach to Business Ethics. Boston: Harvard Business School Press.

Donaldson, T. - Preston, L. E., 1995, "The Stakeholder Theory of the Corporation: Concepts, Evidence and Implications", en: Academy of Management Review, Vol. 20, No. 1, pp. 65-91.

Dreben, B., 2003, "On Rawls and Political Liberalism", en: S. Freeman (ed.) The Cambridge Companion to Rawls. Nueva York: Cambridge University Press.

Freeman, R. E., 1994, "The Politics of Stakeholder Theory: Some Future Directions”, en: Business Ethics Quarterly, Vol. 4, No. 4, pp. 409-421.

Freeman, S., 2003, "Introduction", en: S. Freeman (ed.) The Cambridge Companion to Rawls. Nueva York: Cambridge University Press.

Freeman, S., 2007, Rawls. Nueva York: Routledge.

Freeman, R. E. - Harrison, J. S. - Wicks, A. C., 2007, Managing for Stakeholders: Survival, Reputation and Success. New Haven: Yale University Press.

Friedman, M., 1970, "The Social Responsibility of Business is to Increase its Profits", en: The New York Times Magazine.

Hartman, E. M., 2001, "Moral Philosophy, Political Philosophy, and Organizational Ethics: A Reply to Phillips and Margolis", en: Business Ethics Quarterly, Vol. 11, No. 4, pp. 673-685. 
Hsieh, N., 2005, "Rawlsian Justice and Workplace Republicanism", en: Social Theory and Practice, Vol. 31, No. 1, pp. 115-137.

Marens, R., 2007, "Returning to Rawls: Social Contracting, Social Justice, and Transcending the Limitations of Locke", en: The Journal of Business Ethics, Vol. 75, No. 1, pp. 63-76.

Phillips, R., 2003, Stakeholder Theory and Organizational Ethics. San Francisco: Berrett-Koehler.

Phillips, R. A. - Margolis, J. D., 1999, "Toward and Ethics of Organizations", en: Business Ethics Quarterly, Vol. 9, No. 4, pp. 619-638.

Rawls, J., 1993, Political Liberalism: Expanded Edition. Nueva York: Columbia University Press.

Rawls, J., 1999a, A Theory of Justice, edición revisada, Cambridge: Harvard University Press.

Rawls, J., 1999b, The Law of Peoples. Cambridge: Harvard University Press.

Rawls, J., 2001, Justice as Fairness: A Restatement. Cambrige: Harvard University Press.

Reich, R. B., 2008, Supercapitalism: The Transformation of Business, Democracy, and Everyday Life. Nueva York: Alfred A. Knopf.

Smith, J. D., 2005, "Moral Markets and Moral Managers Revisited", en: Journal of Business Ethics, Vol. 6, pp. 129-141.

Sollars, G., 2002, "The Corporation as Actual Agreement", en: Business Ethics Quarterly, Vol. 12, No. 3, pp. 351-370. 